\title{
ORGYIA BADIA, HY. EDW. AND OTHER NOTES, WITH A TABLE TO SEPARATE THE LARVAE OF ORGYIA.
}

\author{
BY HARRISON G. DYAR, BOSTON, MASS.
}

Orgyia Badia Hy. Edwards. I 88.

I873, Hy. Edw., Proc. Cal. acad. sci., v,

I88r, Hy. Edw., Papilio, i, 62.= antiqua .

I883, Hy. Edw., Papilio, iii, I89.=antiqua.

I887, Hy. Edw., Ent. amer., iii, I47, $s p$. dist?

I89I, Smith, List lep., p. 27.= antiqua.

Does Orgyia badia occur elsewhere than on the Island of Vancouver, B. C.? The larvae found there by myself were quite constant, and correspond exactly with $\mathrm{Hy}$. Edward's original description. They differ structurally from the larvae of $O$. antiqua which were found right across the water at Port Townsend, Wash., and in various places in New England and northern New York. But $O$. badia $q$ $q$ when brought to New York and exposed there, attracted $\delta \delta$ of $O$. antiqua and hybridized with them. It would seem as if $O$. badia was an isolated local race cut off from communication with the parent species by the water surrounding Vancouver Island. If this view is correct, the name should stand for the race. I append brief descriptions of all the early stages of both $O$. badia and $O$. antiqua for comparison.

Orgyia antiqua race badia Hy. Edw.

Egg. - Spherical, a little elongate and flattened on top; smooth, white. with a pale brown spot and ring on top; diameter I $\mathrm{mm}$. Laid closely over the outside of the cocoon of the $q$ moth without any covering whatever.* The eggs hatch the next spring.

First stage. - Head rounded, shiny black; width $0.55 \mathrm{~mm}$. Body blackish, except the

*Mr. Edwards says that the eggs are "surrounded by hairs from the body of the mother," but this is not so. The moth is not supplied with the necessary amount of hair. dorsum of joints 3-4, 9-13, where it is largely whitish, especially on the anterior patch. Cervical shield black. The subdorsal warts on joint 2 are large, all the warts black; hairs black, several from each wart. There are no hair pencils, brush tufts nor retractile tubercles. At the end of the stage a reddish spot appears centrally on joints 9 and 10 .

Second stage. - As before, except that the two retractile tubercles on joints $I 0$ and II have appeared. They are orange red, as are also the bases of the large hair bearing warts on joint 2 . There is a whitish lateral line and the white patches on joints 9 and 13 are orange tinted. Width of head $0.75 \mathrm{~mm}$.

Third stage. - Body black, abdominal feet and venter pale. The dorsal patch on joints 3 and 4 is divided by a black line, and the lateral area is grayish. Subdorsally on joint 2 is a pair, and dorsally on joint 12 a single short, square, black pencil of plumed hairs. On joints $5^{-8}$ are four bush-like tufts of hair, growing from warts $i$ and the upper parts of ii; pale brown or black on joints 5 and 6 , yellowish and smaller on joints 7 and 8. Warts iii-v whitish, the others blackish. Head I.I mm.

Fourth stage. - As in the third stage but the warts are colored as in the next stage. There are no traces of any lateral hair pencils on joints 5 and 6 . Hair pencils over $\mathrm{I} \mathrm{mm}$. long; head $1.55 \mathrm{~mm}$.

Fifth stage. - Head shiny black, labrum paler; width $2.1 \mathrm{~mm}$. Body dark gray, with a dorsal black band, narrow anteriorly and dividing a dorsal whitish patch, broad on joints 5 to 8 and narrower on joints 9-13. Venter pale as are the feet. On joint 9 dorsally, some orange streaks. Warts ii, iii pale orange, $v$ yellowish, vi largely black [i and iv are so small as to be obscure]. Brush. 
tufts on joints 5 and 6 white, brownish or black, on joints 7 and 8 pale yellow or white. Pencils about $1.5 \mathrm{~mm}$. long preceded by some shorter, but equally black hairs. Other hair blackish and yellowish mixed. Retractile tubercles orange red.

Sixth and seventh stages (the 7 th in some of larvae). - As before, except the brush tufts are all alike, brownish white, darker along the crest. There is a yellowish band subdorsally on joints II and 12 , and a substigmatal one, broken on each segment, but reaching the whole length.

Cocoon. - As in all the other species of this genus.

Pupa. - Structurally as in the other species. Smooth, yellowish white, with more or less black shading on the back, in some covering most of the surface and extending on the under side. A few silky white hairs over the surface and in some three tuft-like structures on the back.

Length $\delta$ Io $\mathrm{mm}$., $q$ I $8 \mathrm{~mm}$.; width $\delta$ 3.5 , क $5.5 \mathrm{~mm}$.

Larvae from Nanaimo, B. C.

\section{Orgyia antiqua Linn.*} nova Fitch.

Egg. - As in O. badia; laid without covering.

First stage. - Like O. badia.

Second stage. - As in O. badia, but there are a few short black hairs from the dorsal warts on joints $5-8$. The orange retractile tubercles now first appear.

Third stage. - The hair pencils are now present; I $\mathrm{mm}$. long; also the brush tufts, those on joints 5 and 6 black on joints 7 and 8 white, the one on joint 8 consisting of only a few hairs.

Fourth stage. - Body black, the warts ii and iii red; hair pencils $2.5 \mathrm{~mm}$. long, black.

\footnotetext{
* In Ent. Amer. Mr. Edwards describes accurately stages $\mathrm{i}$ to iii of $O$. nova and then says there is no change to maturity. This may be an oversight as the lateral pencils do not appear till stage iv. But his statements would imply that he was describing $O$. badia. The larvae were from Houghton, Mich.
}

From wart $\mathrm{v}$ on joint 5 is a white hair pencil, not plumed; from wart $\mathrm{v}$ on joint 6 a plumed black one, both these $1.5 \mathrm{~mm}$. long. These lateral hair pencils are not seen in $O$. badia, which the larva otherwise closely resembles,

Fifth stage. - As before. The brush tufts on joints 5 and 6 are faintly brownish, on joints 7 and 8 yellowish, but nearly the same color. The markings are as in O. badia.

Sixth and seventh stages (7th stage some o larvae). - Head shining black, labrum and bases of antennae white; width $2-8 \mathrm{~mm}$.; and $3.5 \mathrm{~mm}$. in the seventh stage. Body dark gray, paler below, legs flesh color. It is marked as in O. badia. There is a pair of plumed black pencils from wart ii on joint 2 , from wart $\mathrm{v}$ on joint 6 and a single one dorsally on joint 12 ; also a pair of simple white pencils from wart $\mathrm{v}$ on joint 5 , and in one example an additional pair of black plumed pencils from wart $\mathbf{v}$ on joint 7 , distinct and only a little shorter than the others. Some short brown hair precedes the black pencil on joint 12. Brush tufts yellowish white or whitish brown, darker along the crest.

Cocoon and pupa as in O. badia.

Larvae from Port Townsend, Wash., Plattsburgh, N. Y. and Campton Village, N. H.

Orgyia leucographa Geyer.

I832, Geyer, Zutr. Samml. exot. Schmett., 33, 373, f. 745-6, Cladophora.

I856, Walker, Cat. Brit. Mus. vii, I723, Orgyia.

1886, Hy. Edwards, Ent. Amer., ii, I3.

I891, Smith, List lep., No. I 55 .

This can hardly be anything else than $O$. leucostigma S. \& A.† I have not seen the

$\dagger$ Since the above went to the printer, $I$ have examined the figure of leucographa in the copy of the Zuträge in the Harvard College library and find that it represents $O$. leucostigma S. \& A. The varietal name proposed by Hy. Edwards for the form without the white spot, viz., var. obliviosa, will stand as valid. It will prove that this has been redescribed by Mr. Beutenmuiller (Psyche, v. $5, \mathrm{p} .3^{00}$ ) as the only character for specific separation between obliviosa and inornata is the difference be. tween "yellow" and "orange" in the coloration of the warts of the larvae. 
original figure, but Walker's diagnosis is no different.

Orgyia sP. Packard.

I89o, Packard, $5_{\text {th }}$ rept. U. S. ent. comm., p. 774 .

Dr. Packard describes a larva appearing much like $O$. antiqua, but says: "It differs from $O$. leucostigma in having a pair of large prothoracic lateral black pencils" [besides the usual subdorsal ones?] and there are "three coral retractile warts." I would like to call particular attention to this form. It evidently differs structurally from any of the known North American Orgyia in having three instead of two retractile tubercles, besides apparently having two pairs of hair pencils on joint 2. It must be an undescribed species. The larvae were found on pine.

The following table will serve to distinguish the mature larvae of Orgyia.
Head red.

Warts pale yellow leucostigma S. \& A. Warts orange . . . inornata Beut. Head yellow . . . . definita Pack. Head black.

Without lateral tufts on joints 5 and 6 .

Pencil on joint 12 yellow, tufted with black . . . . vetusta Boisd.

Pencil on joint 12 black, perhaps preceded by brown.

Three yellow lines on each side gulosa $\mathrm{Hy}$. Ed.

Two yellow lines on each side. Warts bright crimson cana Hy Ed. Warts orange or yellowish badia $\mathrm{Hy} \mathrm{Ed}$.

With lateral tufts on joints 5 and 6 .

Two retractile tubercles antiqua $\mathrm{L}$.

Three retractile tubercles $s p$. Pack.

\title{
SYNOPSIS OF THE N. AMERICAN SPECIES OF MEGACILISSA.
}

\author{
BY WM. J. FOX, PHILAdELPHIA.
}

Labrum biridged, or strongly furrowed down the middle.

Wings not or but slightly fuscous apically. Abdomen dorsally, with exception of first segment entirely black, with black pubescence. . . electa Cr. $\delta$. Abdomen dorsally black, with the apical margins of segments 2-4 with white pubescence. . Tarrowi Cr. $\& \delta$.

Abdomen greenish, without white fasciae. . . mexicana $\mathrm{Cr}$. $q$.

Wings on apical half blue-black; legs reddish; abdomen black, on the sides, beneath and the sixth and seventh dorsal segments with fulvous pubescence. . . . gloriosa n. sp.

Labrum not ridged or furrowed, at the most swollen basally; abdomen fasciate; legs brownish, with brownish pubescence; wings with a yellow tinge eximia Sm. $\delta$.
Megacilissa gloriosa \%.-- Labrum with a long, narrow, medial furrow; clypeus with strong, close punctures, those in the middle confluent and forming transverse rugae; ocelli situated very low down, the anterior one separated but little from the hind margins of the clypeus and is connected with it by a furrow; vertex and cheeks with rather fine, close punctures, those on the cheeks finest and sparsest; first joint of flagellum fully as long or a little longer than the following five joints united, joints 2-5 shortest and about equal in length; tarsal claws armed with a long, acute tooth, in shape somewhat similar to the claw itself; dorsal abdominal segment finely and closely punctured, except apical portion of segments $1-4$, which is depressed and impunctate; enclosure on last dorsal segment strongly furrowed along the lateral borders. Black; tegulae and legs, except the four anterior femora in part, ferruginons; 

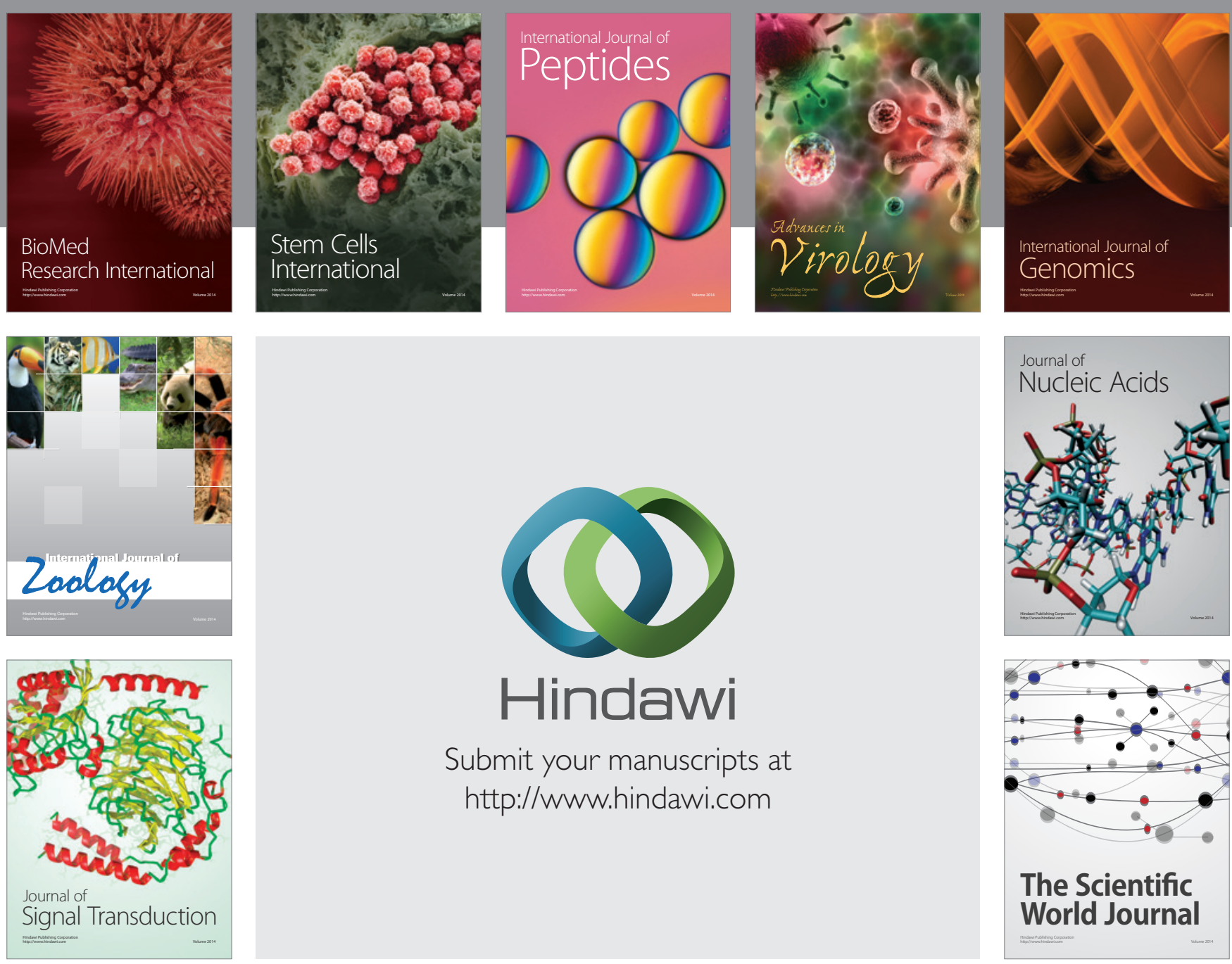

Submit your manuscripts at

http://www.hindawi.com
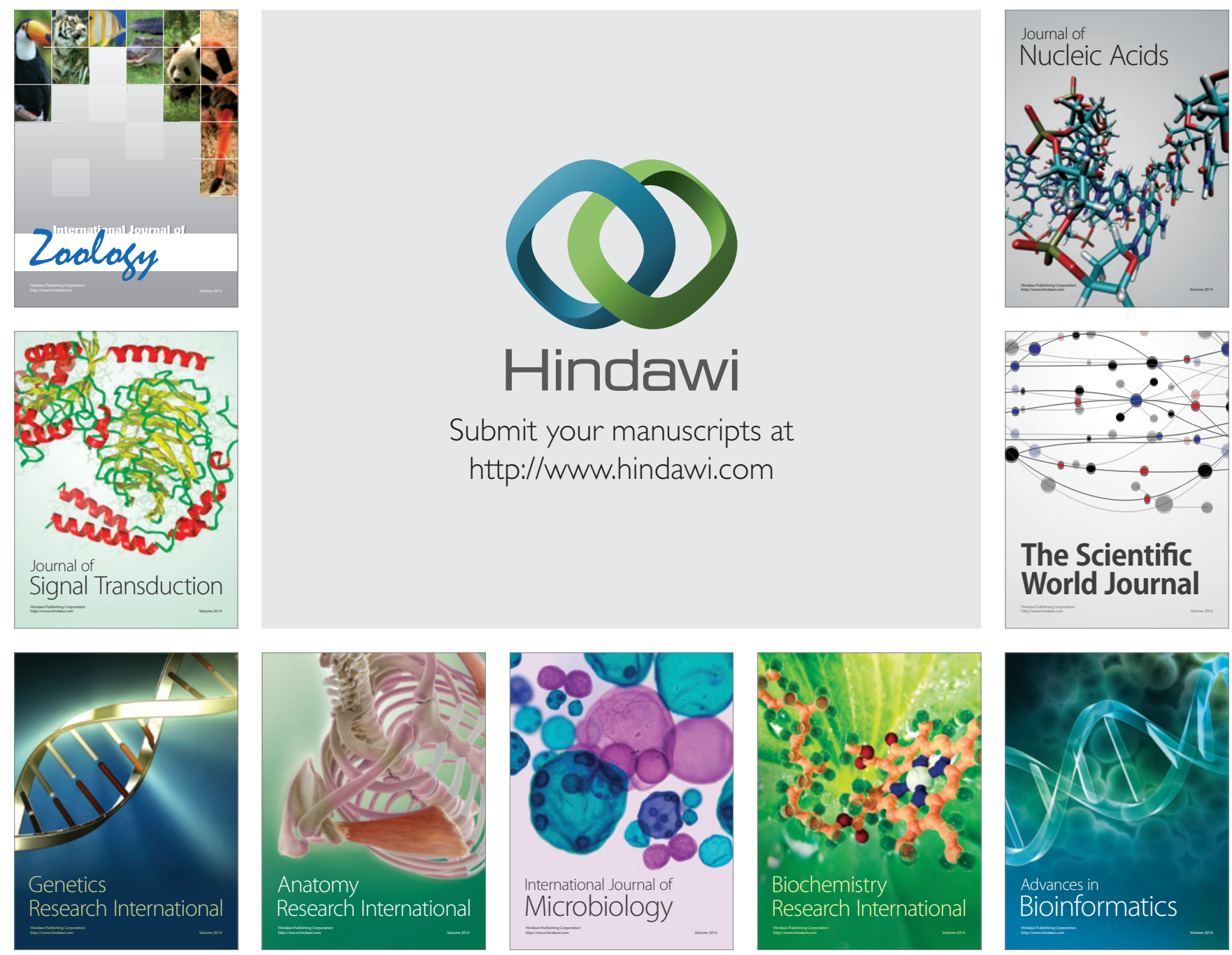

The Scientific World Journal
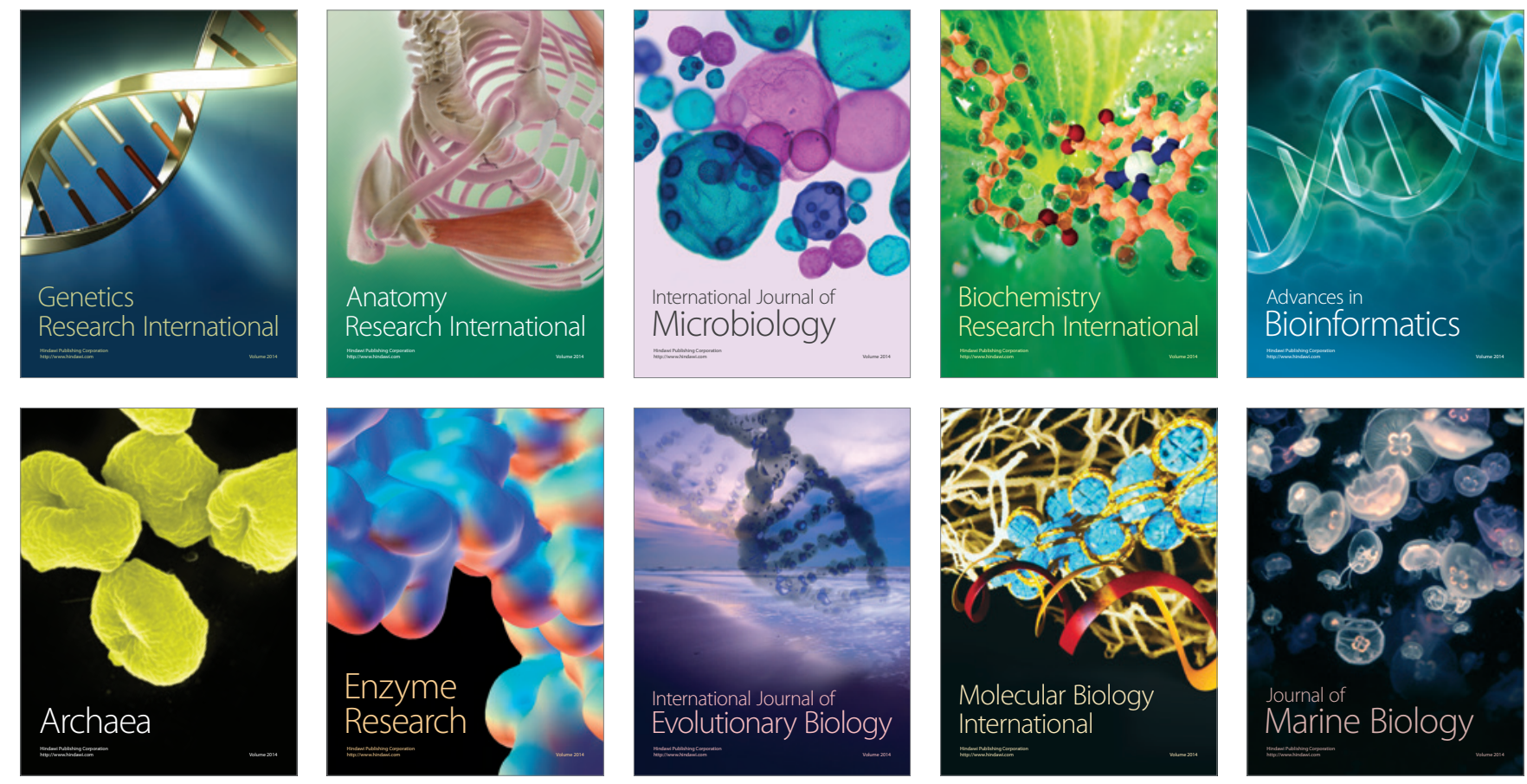